Original Research Article

\title{
Assessment of depression among patients undergoing haemodialysis: a cross-sectional study
}

\author{
Divyashree C. R.*, Nalini G. K., Deepak P., Sahana G. N., Jayashree V. Nagaral, \\ Mohith N., Rakshitha B. V.
}

Department of Pharmacology, Hassan Institute of Medical Sciences, Karnataka, India

Received: 03 April 2019

Revised: 12 April 2019

Accepted: 03 May 2019

*Correspondence to:

Dr. Divyashree C. R.,

Email: divyashree.c.ramesh@ gmail.com

Copyright: (C) the author(s), publisher and licensee Medip Academy. This is an openaccess article distributed under the terms of the Creative Commons Attribution NonCommercial License, which permits unrestricted noncommercial use, distribution, and reproduction in any medium, provided the original work is properly cited.

\begin{abstract}
Background: Depression is the most important neuropsychiatric complication in chronic kidney disease because it reduces quality of life and increases mortality. The beginning of dialysis treatment causes subtle changes in the life of CKD patients, mainly in the physical and social spheres. It affects the self-care of these patients which lead to poor adherence to dialysis. Hence, the present study was conducted to screen for depression.

Methods: This was an observational study among 100 patients undergoing haemodialysis at HIMS, HASSAN. After taking informed consent, subjects were requested to complete Beck, depression Inventory, a 21-question multiplechoice self-report inventory for measuring the severity of depression. Descriptive statistics was applied to infer the findings.

Results: The study population showed depression of mild $(31 \%)$, borderline $(10 \%)$, moderate $(17 \%)$, severe $(7 \%)$ and extreme $(3 \%)$ grade and the remaining subjects did not show depressive symptoms (32\%).

Conclusions: Majority of patients undergoing hemodialysis were depressed. Major risk factors for depression were marital status of the patients, low literacy rate, gender and those started on dialysis recently.
\end{abstract}

Keywords: Beck's depression inventory, Chronic kidney disease, Depression, Hemodialysis

\section{INTRODUCTION}

Depression is well established as a prevalent mental health problem for people with end-stage renal disease (ESRD) and is associated with morbidity and mortality. Current estimates suggest a 20 to $30 \%$ prevalence of depression that meets diagnostic criteria. ${ }^{1}$ Depression is second only to hypertension in frequency as a comorbid diagnosis in patients with ESRD, yet it is understudied and seldom identified or treated adequately in hemodialysis patients. ${ }^{2-}$ ${ }^{6}$ The rapidly increasing numbers of dialysis patients and their increasing medical complexity make it even less likely that depression will be detected due to the many competing demands placed on healthcare providers. ${ }^{7}$
A systematic assessment of depression in hemodialysis patients would supply information about patients' feelings of well being. ${ }^{8,9}$ Depression has several effects on the clinical outcomes of patients undergoing haemodialysis treatment. Depression among this population has been shown to have significant relationship with noncompliance, duration of dialysis treatments, and withdrawal from haemodialysis. ${ }^{10}$

It is vital and essential to screen these patients for depression using suitable tools as the beginning of dialysis treatment causes subtle changes in the life of CKD patients, mainly in the physical and social spheres. For this reason, individuals diagnosed with CKD usually develop 
neuropsychiatric complications. Depression is the most important of them, due to its high prevalence, reduction in quality of life and potential to increase mortality. ${ }^{11,12}$ Therefore, it is to be considered important not only to know the rate and severity of depression in this population but, also to document its clinical presentation and the patient characteristics associated with it routinely.

Beck's Depression Inventory (BDI) is one of the most widely used tests for assessing the severity of depression in this population and was recently modified for dialysis patients due to the high prevalence of symptoms that can mimic the clinical presentation of depression in this population. ${ }^{13}$ There are very few studies conducted in India to study depression among the patients undergoing hemodialysis. This cross sectional study was undertaken to study the prevalence and severity of depression among ESRD patients undergoing hemodialysis at our tertiary healthcare centre.

Aims and objectives of the study was to know the demographic profile of haemodialysis patients with depression and to assess the severity of depression among patients undergoing haemodialysis.

\section{METHODS}

This was a cross-sectional survey of patients with End Stage Renal Disease (ESRD) undergoing maintenance haemodialysis treatment on outpatient basis at Hassan Institute of medical sciences, Hassan, Karnataka. Ethical approval for the study was obtained from Institutional Ethics Committee. The study was conducted over a 4 month duration - May 2018 to August 2018 after obtaining permission from the Nephrology Head.

Patients aged above 18 years of age who agreed to participate in the study were recruited. Subjects were provided with explanation about the purpose of the study, and an informed written consent was obtained from them. Demographic and clinical data were documented. Patients were requested to complete Beck Depression Inventory (BDI), a self-report questionnaire to assess depression. Beck's depression inventory that has been found to be a reliable tool and well validated measure of depression from earlier studies. This questionnaire was translated to Kannada (local language) for those who did not understand English.

It is a 21-question multiple-choice self-report inventory, one of the most widely used psychometric tests for measuring the severity of depression. The lowest possible score is 0 and the highest possible score is 63 .

The score range and their respective interpretation is listed as follows -

- 1-10 - Normal

- 11-16 - Mild mood disturbance

- 17-20 - Borderline clinical depression
- 21-30 - Moderate depression

- 31-40 - Severe depression

- $>40$ - Extreme depression

\section{Inclusion criteria}

- >18years of age of either sex,

- Patients undergoing haemodialysis.

\section{Exclusion criteria}

- Malignancy

- Patients undergoing haemodialysis who are diagnosed to have psychiatric illness and on treatment for the same.

- Those who are intellectually unable to answer questionnaires and illiterates

- Those who refused to participate.

\section{Statistical analysis}

Data was entered onto Microsoft Excel and was analysed using descriptive statistics.

\section{RESULTS}

A total of 123 patients were screened. 16 subjects were excluded as they were illiterates and 7 subjects refused to give consent. Rest 100 subjects were enrolled for the study. The socio-demographic data of the subjects are listed in Tables 1 and 2 .

Table 1: Literacy status among the study population.

\begin{tabular}{|ll|}
\hline Education & Subjects (\%) \\
\hline Primary school & 22 \\
\hline Higher primary school & 12 \\
\hline Secondary school & 20 \\
\hline Intermediate & 22 \\
\hline Degree & 24 \\
\hline
\end{tabular}

Table 2: Occupation of the study subjects.

\begin{tabular}{|ll|}
\hline Occupation & Subjects $(\%)$ \\
\hline Teaching & 3 \\
\hline Typing & 1 \\
\hline Farmer & 15 \\
\hline Home maker & 30 \\
\hline Retired & 16 \\
\hline Self employment & 29 \\
\hline Unemployed & 3 \\
\hline Daily wage worker & 3 \\
\hline
\end{tabular}

Figure 1 depicts the distribution of various grades of depression in the total study population. About $31 \%$ of the study population showed mild depression and $10 \%$ of the population showed higher grades of depression. 


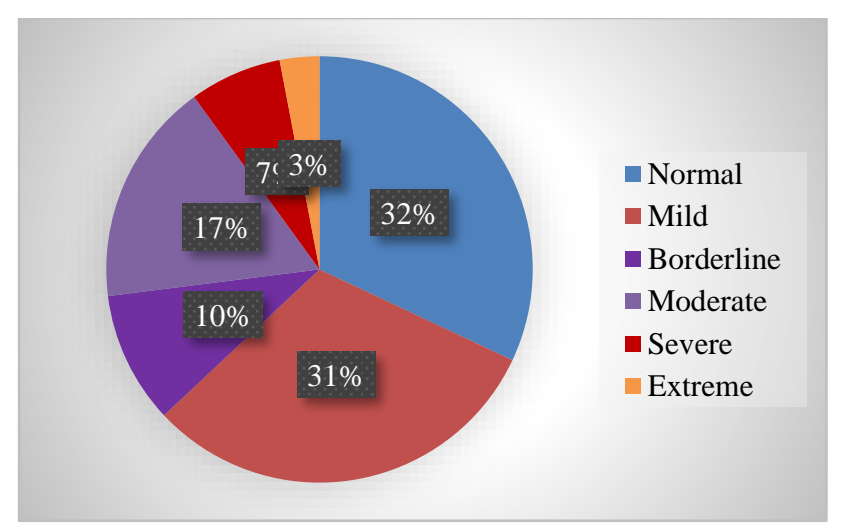

Figure 1: Grades of depression among total study subjects.

The $10 \%$ of the population in this study were from the age group of 30-40 years, $24 \%$ from $40-50$ years, $42 \%$ from 50 60 years, $16 \%$ from $60-70$ years and $8 \%$ were in the range of 70-80 years of age. Figure 2 shows the percentage distribution of various grades of depression among various age groups of our study population.

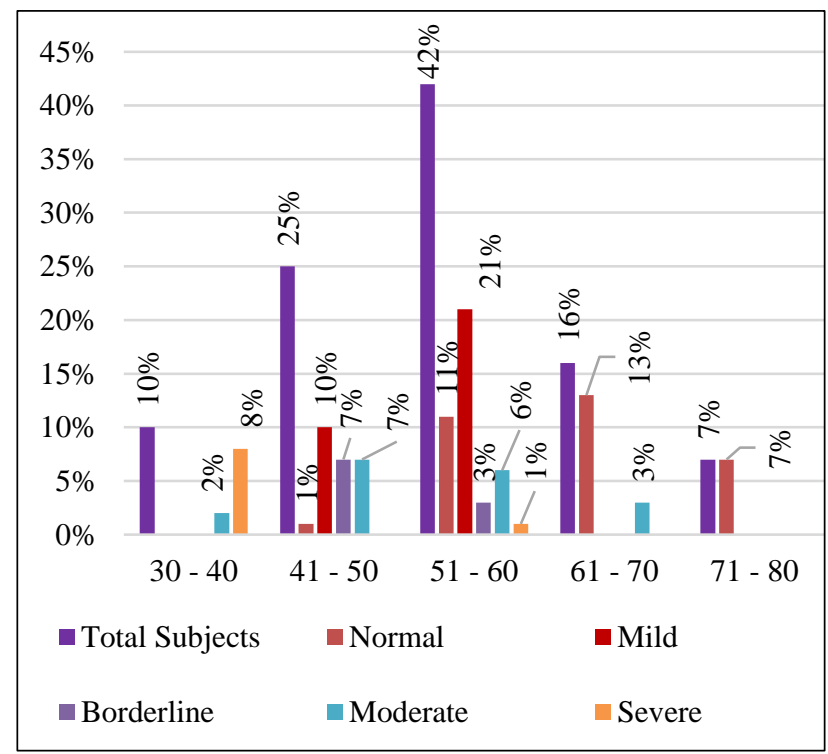

Figure 2: Age and severity of depression.

Figure 3 and 4 depicts the distribution pattern of various grades of depression and the marital status and gender of the study subjects respectively. 5\% each of the subjects were found to be unmarried and widowed respectively, while $72 \%$ of the subjects were married and $18 \%$ were found to be separated from their spouse. Females were found to be more depressed than males in our study.

Table 3 lists the population distribution according to the duration of hemodialysis treatment and we found that majority of the patients were initiated on dialysis fairly recently ( $<3$ months) and only $8 \%$ of the population were on chronic dialysis treatment. Rest of the study population were on hemodialysis from $<1$ year duration.

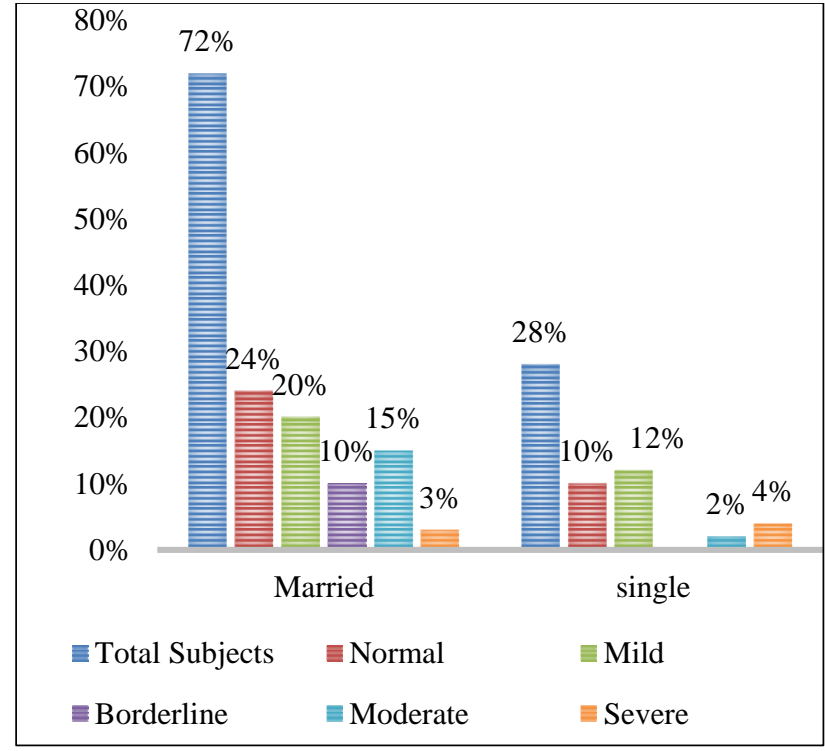

Figure 3: Marital status and severity of depression.

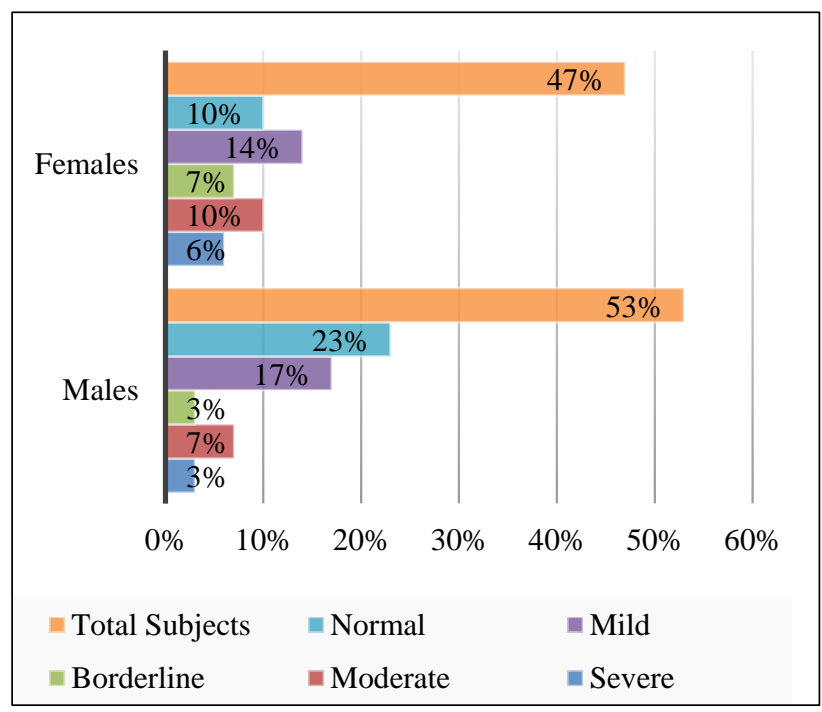

Figure 4: Gender and severity of depression.

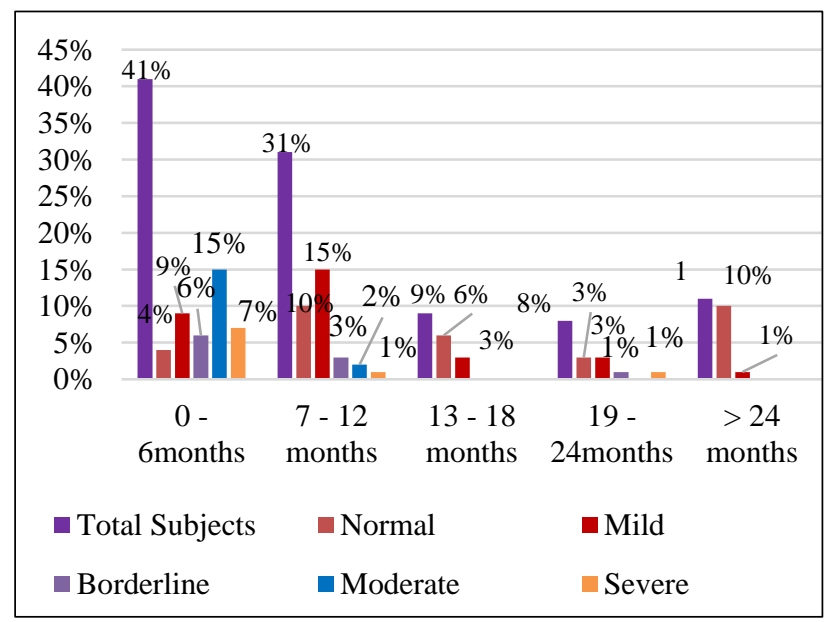

Figure 5: Duration of dialysis and severity of depression. 
Table 3: Duration of dialysis.

\begin{tabular}{|ll|}
\hline Duration & Subjects $(\%)$ \\
\hline $0-3$ months & 26 \\
\hline $4-6$ months & 15 \\
\hline $7-9$ months & 15 \\
\hline $10-12$ months & 15 \\
\hline $13-18$ months & 9 \\
\hline $19-24$ months & 12 \\
\hline$>24$ months & 8 \\
\hline
\end{tabular}

Figure 5 shows the percentage distribution of depression based on duration of dialysis of the study population.

\section{DISCUSSION}

In our study, response to Beck's depression inventory showed that depression was frequently found among CKD patients on hemodialysis. We found that majority of the subjects were mildly depressed (31\%), $10 \%$ of the subjects were borderline depressed, $17 \%$ moderately depressed and $7 \%$ severely depressed. About $3 \%$ of the subjects showed extreme depression and $32 \%$ of the study population did not show depressive symptoms.

Our findings were not on par with that of other similar studies where they found $29 \%, 30 \%$ and $27.4 \%$ of their subjects were reported as suffering from mild, moderate and severe level of depression, respectively. ${ }^{14}$ Another study showed that $16.5 \%$ of patients had no depression, $25.6 \%$ had mild, $45.9 \%$ had moderate and $12 \%$ had severe depression. ${ }^{15}$

Factors that may increase the depression risk are lack of education, socioeconomic factors, marital status, gender, presence of other co-morbidities. Our study showed a trend of more depressive subjects among the younger age groups. In this study, the 30-40 years age group showed $2 \%$ were moderately depressed and $8 \%$ were severely depressed. Among the 40-50 years group, 10\%, 7\% and $7 \%$ subjects showed mild, borderline and moderate depression respectively. In the 50-60 years age group, $21 \%$ showed mild depression, $6 \%$ showed moderate depression and $1 \%$ showed severe depression. Age group above 60 showed almost no depression.

In our study, majority of the subjects were married (72\%) and $3 \%$ an $4 \%$ of the subjects showed severe depression among married and unmarried subjects respectively. $15 \%$ of the married subjects were moderately depressed while, only $2 \%$ of the unmarried subjects were moderately depressed. This was in line with the findings of other studies. ${ }^{15,16}$ This may be because being married and undergoing hemodialysis adds to their expenses, alters their employment status and mental burden as children are considered as the responsibility of the parents until being married in developing countries such as ours.
This study also showed a disparity in the prevalence and severity of depression among males and females. Females showed a higher inclination towards being depressed than males. This finding was similar to other studies where they found that females were almost twice more depressed than males. ${ }^{17}$ Few other studies showed that male subjects were more prone for depression. ${ }^{18-22}$

Most of the depressed patients in our study were less educated, which was similar to the findings of other studies. ${ }^{15,23,24}$ We also found that depression was more common in the initial days of dialysis than in those who have been undergoing dialysis for longer duration.

The limitation of the present study was the relatively small size of the sample. The cross-sectional design allows us to determine associations between variables and not the causal relationships. Moreover, other important aspects such as personal or family problems were not evaluated.

\section{CONCLUSION}

This study alerts us with the importance of earlier diagnosis of depression. Undertaking suitable measures to treat the same may increase the quality of living of these patients. Prevalence of depression was high among younger age group, female gender, married participants and those on the initial sittings of dialysis. Frequency of screening for depression should be increased in view of better health outcomes. Proper orientation of the disease and treatment aspects is to be rendered through counselling using audiovisual aids. Patients and their family diagnosed with depression should be counselled and if required the patients should be started on anti-depressants. Supportive environment should be created at home and work place.

\section{ACKNOWLEDGEMENTS}

Authors would like to thank the Nephrology department for their willingness to help and support during the study.

Funding: No funding sources

Conflict of interest: None declared

Ethical approval: The study was approved by the Institutional Ethics Committee (IEC noIEC/HIMS/018/30-5-2018)

\section{REFERENCES}

1. Cukor D, Coplan J, Brown C, Friedman S, CromwellSmith A, Peterson RA, et al. Depression and Anxiety in Urban Hemodialysis Patients. Clin J Am Soc Nephrol. 2007;2:484-90.

2. Kimmel PL. Depression in patients with chronic renal disease: What we know and what we need to know. J Psychosom Res. 2002;53:951-6.

3. Kimmel PL, Peterson RA. Depression in patients with endstage renal disease treated with dialysis: Has the time to treat arrived? Clin J Am Soc Nephrol. 2006;1:349-52. 
4. Watnick S, Kirwin P, Mahnensmith R, Concato J: The prevalence and treatment of depression among patients starting dialysis. Am J Kidney Dis. 2003;41:105-10.

5. Hedayati SS, Bosworth HB, Kuchibhatla M, Kimmel PL, Szczech LA. The predictive value of self-reported questionnaires compared to physician diagnosis of depression in end stage renal disease patients receiving chronic hemodialysis. Kidney Int. 2006;69:1662-8.

6. United States Renal Data System. 2014 USRDS annual data report: Epidemiology of kidney disease in the United States. National Institutes of Health, National Institute of Diabetes and Digestive and Kidney Diseases, Bethesda, 2014. Available at: https://www.usrds.org/2014/view/.

7. Williams Jr JW, Rost K, Dietrich AJ, Ciotti MC, Zyzanski SJ, Cornell J. Primary care physicians' approach to depressive disorders. Effects of physician specialty and practice structure. Arch Fam Med. 1999;8(1):58-67.

8. Lopes AA, Bragg J, Young E, Goodkin D, Mapes D, Combe $\mathrm{C}$, et al. Depression as a predictor of mortality and hospitalization among hemodialysis patients in the United States and Europe. Kidney Int. 2002;62:199207.

9. Kimmel PL, Peterson RA, Weihs KL, Simmens SJ, Alleyne S, Cruz I, et al. Multiple measurements of depression predict mortality in a longitudinal study of chronic hemodialysis outpatients. Kidney Int. 2000;57:2093-8.

10. DiMatteo MR, Lepper HS, Croghan TW. Depression is a risk factor for noncompliance with medical treatment: meta-analysis of the effects of anxiety and depression on patient adherence. Arch Intern Med. 2000;160:2101-7.

11. Kessler RC, Berglund P, Demler O, Jin R, Koretz D, Merikangas KR, et al. The epidemiology of major depressive disorder: results from the National Comorbidity Survey Replication (NCS-R). JAMA. 2003;289(23):3095-105.

12. Jiang W, Alexander J, Christopher E, Kuchibhatla M, Gaulden LH, Cuffe MS, et al. Relationship of depression to increased risk of mortality and rehospitalization in patients with congestive heart failure. Arch Intern Med. 2001;161(15):1849-56.

13. Grant D, Almond MK, Newnham A, Roberts P, Hutchings A. The Beck Depression Inventory requires modification in scoring before use in a haemodialysis population in the UK. Nephron Clin Pract. 2008;110(1):c33-8.
14. Anjomshoa F, Abdar ME. Depression among hemodialysis patients: a cross-sectional study in southeast of Iran. Inter J Epidemiol Res. 2014;1(1):248.

15. AlDukhayel AR. Prevalence of depressive symptoms among hemodialysis and peritoneal dialysis patients. Int J Health Sci. 2015;9(1):9-16.

16. Anees M, Barki H, Masood M, Mumtaz A, Kausar T. Depression in hemodialysis patients. Pak J Med Sci. 2008;24(4):560-5.

17. Mirza I, Jenkins R. Risk factors, prevalence, and treatment of anxiety and depressive disorders in Pakistan: systematic review. BMJ. 2004;328(7443):794.

18. Jadhav ST, Malagi V, D'Souza CV. Prevalence of depressive symptoms among haemodialysis patients: A cross sectional survey. Inter $\mathbf{J}$ Nursing. 2011;4(1):53-8.

19. Khaira A, Mahajan S, Khatri P, Bhowmik D, Gupta S, Agarwal SK. Depression and marital dissatisfaction among Indian hemodialysis patients and their spouses: a cross-sectional Study. Ren Fail. 2012;34(3):316-22.

20. Rai M, Rustagi T, Rustagi S, Kohli R. Depression, insomnia and sleep apnea in patients on maintenance hemodialysis. Indian J Nephrol. 2011;21(4):223-9.

21. Patel ML, Rekha S, Anil N, Surendra. Anxiety and depression-a suicidal risk in patients with chronic renal failure on maintenance hemodialysis. IJSRP. 2012;2(3):1-6.

22. Vishal V, Timaniya, Dalal MV. Depression and cognitive function impairment in patients undergoing hemodialysis. IJCPCR. 2013;3(2):64-8.

23. Di DC, Di SN, Iannetti E, Carpinteri G, Vitale M, Squatrito R, Catalano D, et al. Quality of life in hemodialyis patients: the effect of educational status. Clin Ter. 2000;151(4):235-9.

24. Armaly Z, Farah J, Jabbour A, Bisharat B, Abd-El Qader A, Saba S, et al. Major depressive disorders in chronic hemodialysis patients in Nazareth: identification and assessment. Neuropsychiatric disease and treatment. 2011;8:329-38.

Cite this article as: Divyashree CR, Nalini GK, Deepak P, Sahana GN, Nagaral JV, Mohith N, et al. Assessment of depression among patients undergoing haemodialysis: a cross-sectional study. Int J Basic Clin Pharmacol 2019;8:1278-82. 